\title{
Tarifa Branca: Discutindo o uso Racional de Energia Elétrica no Ensino de Ciências
}

\section{White Tariff: Discussing the Rational use of Electric Energy in Science Education}

\author{
Andrea Magale Berro Vernier (andreavernier@hotmail.com) \\ Universidade Federal do Pampa - UNIPAMPA \\ Sandra Andréa Berro Maia (sberromaia@hotmail.com) \\ Universidade Federal do Pampa - UNIPAMPA \\ Carlos Maximiliano Dutra (profcarlosmaxdutra@gmail.com) \\ Universidade Federal do Pampa - UNIPAMPA
}

\begin{abstract}
Resumo: O consumo racional da energia elétrica se constitui em uma temática atual e necessária, presente na Base Nacional Comum Curricular. Considerando a relevância do tema apresentamos uma proposta inovadora, desenvolvida no mês de outubro de 2019, em uma Escola de Ensino Fundamental da rede pública estadual de Uruguaina/RS, em uma turma de $9^{\circ}$ ano, onde os estudantes foram motivados a estimar o consumo mensal, de energia elétrica do ambiente familiar através de cálculos e estabelecer um comparativo entre, os valores correspondentes a esse consumo utilizando a tarifa convencional e a Tarifa Branca. Através da prática os estudantes além de estimar e comparar, refletiram sobre o consumo consciente da energia elétrica e a possibilidade de mudar alguns hábitos.
\end{abstract}

Palavras-chave: Energia; Tarifa Branca; Ensino Fundamental.

Abstract: The rational consumption of electric energy is a current and necessary theme, present in the National Common Curricular Base. Considering the relevance of the theme, we present an innovative proposal, developed in October 2019, in an Elementary School of the state public network of Uruguaina/RS, in a 9th grade class, where students were motivated to estimate consumption monthly, of electric energy from the family environment through calculations and to establish a comparison between, the values corresponding to this consumption using the conventional tariff and the white tariff. Through practice, students, in addition to estimating and comparing, reflected on the conscious consumption of electricity and the possibility of changing some habits.

Keywords: Energy; White Tariff; Elementary School.

\section{INTRODUÇÃO}

A energia elétrica é indispensável para muitas das atividades humanas, sendo imprescindível em nosso cotidiano, seu consumo aumenta cada vez mais (GOLDEMBERG, 2000). Mesmo sendo essencial, a energia elétrica se torna cada vez 
mais onerosa e ainda produzida de forma danosa ao meio ambiente. $\mathrm{O}$ aumento no consumo faz com que sejam necessários planejamentos estratégicos para diminuir os impactos ambientais, bem como a possível sobrecarga das redes elétricas, que possam desencadear novas crises de "apagão" como as ocorridas em 2001 e 2002. Esta crise energética constituiu um alerta quanto ao destino da nação, gerando muitas discussões sobre a necessidade de racionalizar o uso de energia (RIBEIRO; NUNES, 2013).

O consumo de energia no mundo cresce cerca de $2 \%$ ao ano e no Brasil tem crescido a uma taxa anual de 2,2\% nos últimos anos. Como principais consequências deste aumento de consumo, podemos citar o acréscimo do uso de combustíveis fósseis e consequentemente maior poluição ambiental. Podemos ainda mencionar o aumento de sobrecarga na rede de eletricidade e paralelo a isso, uma conta de luz cada vez mais onerosa (GOLDEMBERG, 2000). Usar racionalmente a energia elétrica significa diminuir desperdícios, evitando demandas desnecessárias na construção de novas formas de geração de energia contribuindo para a preservação do meio ambiente (COSTA, 2016).

O governo brasileiro vem implantando medidas para que o consumo de energia elétrica seja feito de forma mais racional. Um dos primeiros programas lançados foi o Programa Nacional de Conservação de Energia Elétrica (PROCEL), criado pelo governo federal em 1985 e executado pela Eletrobrás. O programa consiste em ações voltadas para o aumento da eficiência dos bens e serviços e adoção de hábitos de consumo mais conscientes, mais informações podem ser encontradas no site: https://eletrobras.com/pt/Paginas/Procel.aspx. Em 2016 foi aprovada pela Agência Nacional de Energia Elétrica (ANEEL) a aplicação da Tarifa Branca, que começou a ser implantada apenas em 2018, conforme site: https://www.aneel.gov.br/tarifa-branca.

Familiarizar os estudantes com a temática da energia, e propor o estabelecimento de relações entre as diferentes grandezas através de propostas inovadoras, onde o aluno é o protagonista e questionador frente a realidade é uma necessidade. Como reitera a Base Nacional Comum Curricular (BNCC). "Além disso, espera-se que estabeleçam e utilizem relações entre essas grandezas e entre elas e grandezas não geométricas, para grandezas derivadas como densidade, velocidade, energia, potência, entre outras." (BRASIL, p. 275, 2017).

A BNCC destaca ainda a importância da utilização sustentável de recursos e a reflexão acerca do papel de cada sujeito na preservação do ambiente de um modo geral, “(...) é necessário que ele seja estimulado a pensar em saneamento básico, geração de energia, impactos ambientais". (BRASIL, p. 329, 2017). 
Malinoski e Miquelin (2020) realizaram um levantamento sobre a abordagem da temática "energia" junto a produtos educacionais gerados em cursos de Mestrado Profissional em Ensino de Ciências encontrando apenas 3 trabalhos no período de 2015 a 2018, demonstrando que essa temática tem um grande potencial a ser explorado. Wirzbicki et al. (2019) realizou estudo do conceito de "energia" e suas relações com o metabolismo em livros didáticos de Biologia do Ensino Médio; bem como aplicou entrevistas junto a professores de Biologia e a alunos verificando o processo de ensinoaprendizagem e o desenvolvimento desse conceito nos estudantes, destacando a importância do papel do professor em uma abordagem mais crítica e contextualizada dos conteúdos/conceitos estruturados nos parâmetros curriculares nacionais e presentes nos livros didáticos. Travain et al. (2018) quando se referem as diferentes questões abordadas por professores de ciências, destacam a preocupação com alguns temas, entre eles o consumo consciente de energia, reiteram que a temática favorece uma mudança de comportamento, promovendo a conscientização sobre problemas sociais. Dias et al. (2006) ampliam em seu trabalho, a ideia de consumo racional da energia, trazendo uma avaliação comparativa dos impactos de dois tipos de veículos de transporte de pessoas, o particular e o coletivo, segundo os autores é necessário a implementação de comportamentos que visem o uso racional de energia.

Morales e Giacomelli (2019) desenvolveram projeto de eficiência energética e consumo racional de energia elétrica em residências junto a alunos de uma escola de Ensino Fundamental e destacam que as atividades promovem conscientização do consumo energético e custo de diferentes equipamentos e eletrodomésticos com uma mudança de hábitos dos alunos e suas famílias. Trevisan (2016) explorou pela perspectiva da matemática a conta de energia elétrica analisando o consumo em $\mathrm{kWh}$ e os impostos existentes; também aborda o consumo energético de equipamentos propondo atividades aos alunos que envolvem gráficos e estudo da função afim.

\section{MAIS INFORMAÇÕES SOBRE A TARIFA BRANCA}

Segundo Figueiró (2013), os consumidores de energia são caracterizados por consumirem baixa, média e alta tensão, inicialmente os que consumiam média e alta tensão tinham seu consumo tarifado partindo de sinalizações diferenciadas de hora, dias da semana e período do ano, enquanto os consumidores de baixa tensão eram tarifados por uma tarifa que independe dessas variáveis. O autor salienta ainda que os consumidores de baixa tensão, por uma maior concentração de consumo em momentos específicos, compreendem o grupo responsável pelos maiores investimentos na ampliação do sistema de distribuição de energia. 
Tendo em vista os elementos mostrados acima em 2010 começou a ser discutida na Audiência Pública (AP) n 120/2010, uma nova alternativa tarifária, chamada Tarifa Branca (TB), que objetiva motivar os consumidores, que se enquadravam na categoria de baixa tensão, utilizar de forma mais racional a energia elétrica. Inicialmente em 2018 foi disponibilizada aos consumidores atendidos em baixa tensão, com média anual de consumo mensal superior a $500 \mathrm{kWh} / \mathrm{mês}$; em 2019 para unidades consumidoras com média anual de consumo mensal superior a $250 \mathrm{kWh} / \mathrm{mês}$ e em $1^{\circ}$ de janeiro de 2020 para todas as unidades consumidoras com média anual de consumo mensal de 127, 220, 380 ou 440 Volts, compreendendo a classe B, subgrupos B1, B2 e B3.

A Tarifa Branca não está disponível para a subclasse de tarifa social, atribuída a consumidores de baixa renda e para a Iluminação Pública (subgrupo B4). Trata-se de uma tarifa de caráter opcional, podendo o consumidor aderir e caso não perceba vantagens pode voltar a tarifa convencional, a operadora tem prazo de 30 dias para fazer as alterações solicitadas pelo consumidor. $\mathrm{O}$ diferencial dessa modalidade é possuir tarifas diferenciadas de acordo com três faixas horárias conforme o grau de ociosidade do sistema de distribuição de energia: fora da ponta das $23 \mathrm{~h}$ às $17 \mathrm{~h}$, momento de alta ociosidade do sistema, intermediária correspondendo ao período de $18 \mathrm{~h}$ e de $22 \mathrm{~h}$ (média ociosidade do sistema), ponta das $19 \mathrm{~h}$ às $21 \mathrm{~h}$, mais oneroso por ser um momento de baixa ociosidade do sistema.

Buscando no endereço eletrônico https://www.aneel.gov.br/ranking-das-tarifas, temos informações atualizadas, sobre as tarifas aplicadas por todas as distribuidoras de energia elétrica do país, o que facilita a busca por informações quanto aos valores, tanto da tarifa convencional, quanto das tarifas diferenciadas que constituem a Tarifa Branca.

É importante antes de o consumidor optar pela Tarifa Branca, fazer uma análise de seu perfil de consumo, e um comparativo com o consumo nos períodos de ponta e intermediário, determinado pela distribuidora que o atende. Uma dica importante diante dessa análise, é observar que quanto maior for a diferença entre a Tarifa Branca fora de ponta e a Tarifa Convencional, maiores serão os benefícios de optar pela Tarifa Branca.

Nesse trabalho apresentamos atividades desenvolvidas com estudantes do Ensino Fundamental relacionadas a uma maior conscientização quanto ao consumo de energia considerando o consumo energético de equipamentos e eletrodomésticos, o consumo energético mensal residencial e a viabilidade da adoção da Tarifa Branca.

\section{METODOLOGIA}


Seguimos a metodologia dos três momentos descritos por Delizoicov et al. (2002) a problematização, a organização e a aplicação do conhecimento. Entendendo como problematização um momento onde são apresentadas situações reais, questionamentos, fomentando a discussão diante das distintas posições dos estudantes frete ao tema, buscando estabelecer a necessidade da busca das respostas. Já a organização do conhecimento materializa-se no aprofundamento do tema, é o diálogo entre a necessidade das respostas e os conceitos fundamentais para a compreensão da situação problematizada. A aplicação do conhecimento, se constitui em capacitar o estudante a aplicar o conhecimento, articulando conceitos a situações cotidianas. Tendo em conta esses príncipios apresenta-se o Quadro 1 em que estruturamos o desenvolvimento da atividade Tarifa Branca no contexto dos três momentos.

Quadro 1 - Organização da proposta a luz dos três momentos pedagógicos.

\begin{tabular}{|c|c|c|}
\hline \multicolumn{3}{|c|}{ Viabilidade da Tarifa Branca } \\
\hline Estudo da realidade & Organização do conhecimento & Aplicação do conhecimento \\
\hline $\begin{array}{l}\text { Qual é o consumo } \\
\text { mensal de energia } \\
\text { elétrica em sua } \\
\text { residência? } \\
\text { Qual a relação entre } \\
\text { consumo de energia } \\
\text { elétrica e a conta emitida } \\
\text { pela concessionaria de } \\
\text { energia? } \\
\text { A unidade que } \\
\text { representa a energia } \\
\text { elétrica está relacionada } \\
\text { a que unidade de tempo? } \\
\text { Dos equipamentos } \\
\text { domésticos qual } \\
\text { consome maior energia e } \\
\text { qual consome menor } \\
\text { energia? }\end{array}$ & $\begin{array}{l}\text { Consolidação dos conceitos } \\
\text { de potência e consumo } \\
\text { elétrico. } \\
\text { Caracterização do consumo e } \\
\text { dos tributos que constituem o } \\
\text { valor a ser pago pela energia } \\
\text { doméstica. } \\
\text { Revisar o conceito de } \\
\text { porcentagem } \\
\text { Interação com diferentes } \\
\text { unidades de medida em } \\
\text { especial com as relacionadas } \\
\text { a energia elétrica. } \\
\text { Conceituação e reflexão } \\
\text { acerca do tema Consumo } \\
\text { Consciente e Economia de } \\
\text { Energia. }\end{array}$ & $\begin{array}{l}\text { Realização da pesquisa em } \\
\text { seu ambiente familiar. } \\
\text { Determinação da estimativa } \\
\text { do consumo médio de } \\
\text { energia elétrica. } \\
\text { Reconhecimento dos } \\
\text { elementos que compõe a } \\
\text { conta de energia elétrica. } \\
\text { Determinação do valor a ser } \\
\text { pago optando pela Tarifa } \\
\text { Branca. } \\
\text { Realizar comparativo entre } \\
\text { os valores a serem pagos } \\
\text { com e sem a opção da Tarifa } \\
\text { Branca. } \\
\text { Determinação da possível } \\
\text { economia a partir da opção } \\
\text { pela Tarifa Branca. }\end{array}$ \\
\hline
\end{tabular}

Fonte: adaptado Delizoicov et al. P. 316 e 317 (2017) 
Após questionamentos iniciais sobre conceitos de consumo, potência e de unidades de medida da energia elétrica; será realizado um teste, conforme o Quadro 2, que servirá de pré-teste, e será novamente aplicado no final da atividade como pós-teste.

Quadro 2: Questões referente ao pré-teste e pós-teste.

Questionamentos

a) Qual é o consumo de energia elétrica em sua residência?

b) Em sua opinião quais aparelhos consomem mais energia?

c) Você sabe o que significa Tarifa Branca?

Fonte: Produzida pelos autores

Na sequência será realizada uma aula expositiva aprofundando os conceitos de consumo, potência e de unidades de medida da energia elétrica e aplicação dos conhecimentos resolvendo situações problema. Após a aula expositiva será proposta uma atividade prática envolvendo a Tarifa Branca com os seguintes passos:

Passo 1: Realização da pesquisa de consumo de energia no ambiente familiar. Os estudantes receberão as orientações para o preenchimento do instrumento de pesquisa constante no Quadro 3.

O Quadro 3 consta em sua parte superior, dois blocos: no primeiro a fórmula do consumo (kWh) e no segundo um exemplo ilustrativo, logo abaixo a indicação do objetivo da pesquisa "Estimar o consumo e a potência média de aparelhos eletrodomésticos" e em sua parte inferior seis colunas com várias linhas, na primeira coluna temos a indicação do aparelho eletrodoméstico que será investigado, na segunda, indicação pela letra maiúscula do alfabeto (A) temos a prévia da potência dada em Watt, na terceira coluna (B) destinada a indicação da quantidade de aparelhos, na quarta coluna (C) a indicação do tempo de consumo diário de cada aparelho, na quinta coluna (D) temos a estimativa do número de dias, por mês, de utilização do aparelho e por fim na última coluna temos o consumo dado em ( $\mathrm{kWh} / \mathrm{mês})$, nas linhas consta uma lista com vários eletrodomésticos e mais alguns espaços vazios para que o estudante possa acrescentar algum aparelho que não tenha sido incluído previamente na lista.

Quadro 3: Tarefa de pesquisa apresentada aos estudantes.

\begin{tabular}{|l|l|} 
Consumo $(\mathrm{kWh})=\frac{\text { Potêneía }(\mathrm{W}) \cdot \frac{\text { horas }}{\text { dĩas }} \cdot \frac{\text { dias }}{\text { mês }}}{1000}$ & $\begin{array}{l}\text { Como por exemplo, um ferro de 1000 W, que é } \\
\text { utilizado 1 hora por dia, 3 vezes por semana }(12 \\
\text { dias por mês }):\end{array}$ \\
Consumo $(\mathrm{kWh})=$ \\
$\frac{1000 \mathrm{~W} \cdot 1 \text { hora } \cdot 12 \text { dias }(\text { no mês })}{1000}=$ \\
$12 \mathrm{kWh} / \mathrm{mês}$
\end{tabular}


CONSUMO E POTÊNCIA MÉDIA DE APARELHOS ELETROMÉSTICOS

\begin{tabular}{|l|r|l|l|l|l|}
\hline Aparelho & (A) Potência & $\begin{array}{l}\text { (B) } \\
\text { Quantidade }\end{array}$ & $\begin{array}{l}\text { (C) Tempo } \\
\text { de consumo } \\
\text { em horas } \\
\text { por dia }\end{array}$ & $\begin{array}{l}\text { (D) Número } \\
\text { de dias por } \\
\text { mês }\end{array}$ & $\begin{array}{l}\text { Consumo (kWh/mês) } \\
(\mathrm{A}) \times(\mathrm{B}) \times(\mathrm{C}) \times(\mathrm{D})\end{array}$ \\
\hline Aparelho de som & 100 & & & & 100 \\
\hline Aspirador de pó & 100 & & & & \\
\hline Cafeteira & 300 & & & & \\
\hline Computador & 120 & & & & \\
\hline $\begin{array}{l}\text { Condicionador de } \\
\text { ar }\end{array}$ & 0 & & & & \\
\hline Chuveiro elétrico & 500 & & & & \\
\hline
\end{tabular}

Fonte: Produzida pelos próprios autores.

Passo 2: Realizar os cálculos da estimativa de consumo médio mensal da residência, tendo como base o levantamento de dados do ambiente familiar provenientes da pesquisa, fazendo o somatório dos resultados apurados na última coluna.

Passo 3: Determinar os valores a serem pagos pelo consumo de energia e fazer um comparativo, entre o valor a ser pago pelo consumo mensal de energia elétrica, tendo como parâmetro a utilização ou não da Tarifa Branca, a partir do preenchimento e cálculos propostos no Quadro 4.

O Quadro 4 é composto por oito colunas e sete linhas. Na primeira coluna temos a indicação da distribuidora e o mês de realização da atividade, na segunda e na terceira colunas temos os tributos, Tarifa de Uso do Sistema de Distribuição (TUSD) e a Tarifa de Energia (TE), estes dados são fixados anualmente e foram levantados junto a distribuidora local RGE. Na quarta coluna temos o somatório dos dois tributos TUSD + TE. Na quinta e sexta coluna temos a ilustração de um exemplo do consumo de energia em $\mathrm{kWh}$ e o valor a ser pago pelo consumidor. Nas últimas duas colunas o consumo e o valor a ser pago pelo estudante em sua estimativa.

Nas linhas temos a descrição da tarifa normal, dos indicativos de custo subdividido em três categorias na opção pela Tarifa Branca: ponta, intermediária e fora da ponta categorias estas organizadas a partir de horários e dias da semana, e a indicação da economia diante da opção pela Tarifa Branca.

Quadro 4: Estimativa da economia ao adotar a Tarifa Branca.

\begin{tabular}{|l|l|l|l|l|l|l|l|}
\hline $\begin{array}{l}\text { Distribuidora RGE } \\
\text { Custo kWh Outubro } \\
2019\end{array}$ & $\begin{array}{l}\text { TUSD } \\
(\mathrm{R} \$)\end{array}$ & TE $(\mathrm{R} \$)$ & $\begin{array}{l}\text { Total } \\
(\mathrm{R} \$)\end{array}$ & $\begin{array}{l}\text { Energia } \\
\text { Exemplo } \\
\text { em kWh }\end{array}$ & $\begin{array}{l}\text { Total a } \\
\text { pagar } \\
\text { Exemplo }\end{array}$ & $\begin{array}{l}\text { Sua } \\
\text { energia }\end{array}$ & $\begin{array}{l}\text { Total a } \\
\text { pagar }\end{array}$ \\
\hline Tarifa Normal & 0,454 & 0,422 & 0,876 & 500 & 438 & & \\
\hline Ponta (18-21 h) & 0,898 & 0,673 & 1,571 & 25 & 39,27 & & \\
\hline
\end{tabular}




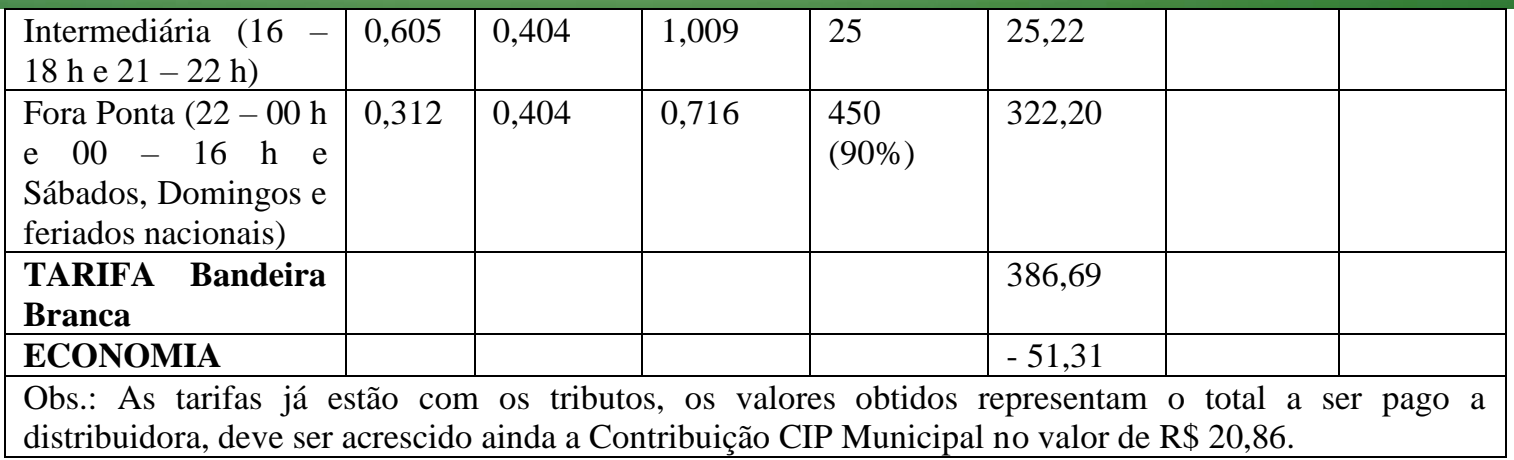

Fonte: Produzida pelos próprios Autores

Após a realização da atividade prática de Tarifa Branca será aplicado o pós-teste realizando as mesmas questões do Quadro 2.

Por fim propõe se uma atividade de compartilhar no coletivo os resultados obtidos com a socialização das aprendizagens construídas.

\section{APLICAÇÃO E RESULTADOS}

A prática foi desenvolvida no mês de outubro, em uma Turma de $9^{\circ}$ ano da Escola Estadual de Ensino Fundamental Hermeto José Pinto Bermudez de Uruguaiana/RS. A turma é composta por 24 estudantes, com idades que variam entre 13 e 16 anos. A escola está localizada na periferia da cidade. A proposta objetiva proporcionar atividades inovadoras favorecendo o engajamento e a motivação dos estudantes no desenvolvimento e na apropriação de conceitos científicos.

Os estudantes são críticos e curiosos, a metodologia previa quatro períodos letivos para desenvolvimento da proposta, porém, durante sua realização percebeu-se a necessidade de ampliar em dois períodos sua aplicação, totalizando seis períodos de cinquenta minutos cada, divididos em três etapas. Com isso revisou-se o estudo da porcentagem e conceitos necessários para a determinação dos valores a serem pagos para cada uma das três categorias que compõe a Tarifa Branca.

Enfatizamos a importância de práticas inovadoras que ultrapassem os espaços escolares, instrumentalizando os estudantes a serem protagonistas de transformações em seu meio, e a busca por atitudes de conscientização sobre sustentabilidade perpassa pela temática da energia. Destacamos que diante da aplicação da proposta percebeu-se uma evolução nos conceitos apresentados pelos estudantes. 
Os estudantes ao trabalharem com a temática da energia, foram desafiados a responder alguns questionamentos como forma de motivá-los para o desenvolvimento da proposta, na sequência foi apresentado o pré-teste (Quadro 2).

Os estudantes apresentaram muita motivação e interesse ao realizar a pesquisa no ambiente familiar, o que favoreceu na busca de estratégias para facilitar o preenchimento da tabela do consumo e a potência média dos eletrodomésticos que compõe o ambiente familiar.

Tendo em mãos o consumo mensal e o conhecimento das tarifas e encargos que incidem no valor total a ser pago mensalmente pela energia consumida, os estudantes determinaram o valor a ser pago considerando a Tarifa Normal. Na sequência, conhecendo o conceito e as informações referente a Tarifa Branca, os estudantes foram desafiados a calcular uma estimativa do gasto para esse mesmo consumo caso aderissem à Tarifa Branca.

Depois de desenvolverem cálculos (como: regra de três, multiplicações, adições e subtrações) os estudantes interagiram positivamente com a proposta demonstrando satisfação ao observar os resultados de suas estimativas de que em média $90 \%$ do consumo era realizado em horários mais econômicos (se adotados a Tarifa Branca). De um modo geral $92 \%$ dos estudantes constataram com seus cálculos, que poderiam beneficiar-se desse recurso gerando economia no valor pago pelo resultante do consumo de energia elétrica.

Os estudantes realizaram um comparativo entre os horários de maior consumo de energia (aqueles em que os equipamentos de maior potência eram utilizados pela maioria das famílias) e as faixas de tarifação para o consumo apresentadas pela Tarifa Branca. Através dessa análise, eles constataram que em alguns casos era necessário promover algumas mudanças de hábito para que o benefício fosse válido. A reflexão acerca do consumo consciente e a busca de alternativas possíveis para melhor gerenciar o consumo também estiveram presentes durante a realização da proposta.

Ao analisar as respostas obtidas com a aplicação do pré-teste, e ao compará-las com as respostas atribuídas às mesmas questões, porém, realizadas após a efetivação da proposta, constata-se no que se refere à questão 1 no pré-teste, que cerca de $70 \%$ dos estudantes não sabiam precisar o consumo familiar fazendo aproximações e $30 \%$ deles 
responderam não saber. No pós-teste $100 \%$ dos estudantes responderam saber o valor referente ao consumo familiar de energia, alguns até referiram-se ao consumo em kWh/mês.

No que se refere à segunda questão constatou-se no pré-teste a indicação de principais equipamentos quanto ao consumo de energia: geladeira, computador, carregador de celular, chuveiro elétrico, TV, máquina de lavar, ventiladores e ar condicionado. Em relação ao pós-teste percebe-se que os estudantes em sua maioria, de certa forma, diminuíram sua indicação, predominando: o chuveiro elétrico, o forno elétrico, freezer e ar condicionado.

Quanto à última questão no pré-teste $91 \%$ dos estudantes responderam não saber do que se tratava, um deles respondeu que era quando não havia o consumo de energia e outro que se referia a um consumo igualitário. Já ao analisar as respostas apresentadas no pós-teste constata-se que $75 \%$ dos estudantes responderam de forma satisfatória registrando a definição correta para Tarifa Branca, enquanto 20\% dos estudantes registram não saber e 5\% deles responderam, ser quando se tem um consumo menor de energia.

Para finalizar o trabalho foi realizada uma plenária onde após a apresentação e discussão dos resultados dos pré e pós-testes, os estudantes apresentaram para os colegas os resultados de suas aprendizagens. Destaca-se que durante as apresentações muitos salientaram a importância do consumo consciente, tanto no que se refere a questão econômica quanto às questões ambientais.

\section{CONSIDERAÇÕES FINAIS}

O presente trabalho constitui-se em uma proposta de abordagem prática da temática de "Energia", em especial a energia elétrica, discutindo o consumo residencial o seu uso racional e a viabilidade de adesão da Tarifa Branca proposta pela ANEEL, que visa redirecionar parte do consumo reduzindo a alta demanda energética do sistema nos chamados horários de pico.

O aprofundamento dos conhecimentos sobre Tarifa Branca, com a tarifação diferenciada para cada período, destacou a importância de se conhecer o perfil de cada família. Os estudantes realizaram levantamento do consumo de energia em suas residências bem como os períodos de maior utilização; e através desse conhecimento, 
os estudantes verificaram as possibilidades de realizar mudanças nesse perfil de modo a deslocar o consumo de energia elétrica mais oneroso, dos períodos de ponta (das $19 \mathrm{~h}$ às 21h), para períodos fora de ponta (das $23 \mathrm{~h}$ às $17 \mathrm{~h}$ ). Salientaram também a necessidade de desenvolver uma consciência, no sentido de disciplinar o gerenciamento do consumo ao longo do ano. De modo a garantir uma economia permanente não somente pela mudança de horários de utilização; mas também evitar o desperdício com um uso mais eficiente da energia.

Leite e Radetzke (2017) investigaram a compreensão de contextualização no Ensino de Ciências por parte de professores da Educação Básica indicando um senso comum em que a contextualização deve trazer o conteúdo para o "universo" do aluno, como forma de "facilitação" do entendimento de conceitos. Segundo Leite e Radetzke (2017) a contextualização atinge sua finalidade quando promove a compreensão de problemas sociais e propõe como o aluno pode através do conhecimento adquirido atuar no meio e transformá-lo.

Nesse sentido, a atividade proposta de Tarifa Branca cumpre o seu papel de contextualização da temática de energia, indo além do senso comum de conectar os conhecimentos escolares com o cotidiano e conduzindo os estudantes ao uso do conhecimento na formação de uma consciência a cerca do uso racional da energia.

\section{REFERÊNCIAS}

Agência Nacional de Energia Elétrica- ANEEL. Disponível em: https://www.aneel.gov.br/tarifa-branca. Acesso em 18 de maio de 2020.

BRASIL. Ministério da Educação. Base nacional comum curricular. Brasília, DF, 2017. Disponível em: http://basenacionalcomum.mec.gov.br/images/BNCC_EI_EF_110518_versaofinal_site. pdf. Acesso em 18 maio de 2020.

COSTA, M. D. A. O Administrador e o uso racional da energia elétrica. Revista Eletrônica Ciências Empresarias, v. 8, n. 12, p. 24-34, 2018. Disponível em: http://periodicos.unifil.br/index.php/revista-empresrial/article/view/491/420. Acesso em 26 de maio de 2020.

DELIZOICOV, D., Angotti, J. A. e Pernambuco, M. M. (2002). Ensino de Ciências: Fundamentos e métodos. São Paulo: Cortês. 
FIGUEIRÓ, I. C. et al. A tarifa horaria para os consumidores residenciais sob o foco das Redes Elétricas Inteligentes-REI. 2013. Disponível em: https://repositorio.ufsm.br/handle/1/8527. Acesso em 17 em maio 2020.

GOLDEMBERG, J. Pesquisa e desenvolvimento na área de energia. São Paulo Perspec., São Paulo, v.14, n.3, p.91-97, July, 2000. Disponível em: https://www.scielo.br/scielo.php?script=sci_arttext\&pid=S0102$\underline{88392000000300014 \& \operatorname{lng}=e n \& n r m=\text { iso. }}$. Acesso em 19 de maio de 2020.

LEITE, F.; RADETZKE, F. Contextualização no Ensino de Ciências: Compreensões de professores da Educação Básica. Revista VIDYA, v.37, n.1, p. 273-286, 2017.

MALINOSKI, A.; MIQUELIN, A. Discussões acerca do Mestrado Profissional em Ensino de Ciências: levantamento de produtos educacionais relacionados à Energia. Revista Insignare Scientia - RIS, v. 3, n. 1, p. 23-41, 2020.

MORALES, A. C.; GIACOMELLI, P. Promovendo a consciência sobre o uso racional de energia elétrica em residências: uma proposta de atividade. Scientia cum Industria, v. $7, \quad$ n. $1, \quad$ p. 1-6, 2019. Disponível em: http://www.ucs.br/etc/revistas/index.php/scientiacumindustria/article/view/6919. Acesso em 15 de maio de 2020.

RIBEIRO, Elisalvo Alves; NUNES, Maria Augusta Silveira Netto. Simulador de consumo de energia elétrica. Revista GEINTEC-Gestão, Inovação e Tecnologias, v. 3, n. 4, p. 016-029, 2013. Disponível em: http://www.revistageintec.net/index.php/revista/article/view/147/322. Acesso em 28 de maio de 2020.

TRAVAIN, S. A.; TRAVAIN, C.; ASSIS, A. A visão dos alunos do ensino fundamental sobre a caloria dos alimentos e seu impacto na saúde. Revista Insignare Scientia RIS, v. 1, n. 3, p. 1-17, 2018.

TREVISAN, M.C. A Matemática na conta de energia elétrica: um estudo sobre gráficos e função afim aplicado no ensino médio. Monografia de Especialização, Universidade Federal de Santa Maria, Santa Maria, 2016. Disponível em: https://repositorio.ufsm.br/bitstream/handle/1/15011/TCCE_EMEM_EaD_2016_TREV ISAN_MARLON.pdf?sequence=1\&isAllowed=y. Acesso em 30 de maio de 2020.

WIRZBICKI, S.; DEL PINO, J.; PANSERA-DE-ARAÚJO, M. O Conceito Energia nas Interações entre Professores e Estudantes Mediadas pelos Livros Didáticos de Biologia. Revista Insignare Scientia - RIS, v. 2, n. 1, p. 138-150, 2019. 